Therese Monique D.G. Gutierrez, MD

Francisco Jesus V. Lerma, Jr., MD

Department of Otorhinolaryngology Head and Neck Surgery

University of Santo Tomas Hospital

\section{Clinical Profile of Filipino Patients with Epistaxis in a University Hospital}

\begin{abstract}
Objective: To present the demographic profile, etiology and treatment outcome of patients presenting with epistaxis in our local setting.
\end{abstract}

\section{Methods:}

$\begin{array}{ll}\text { Design: } & \text { Retrospective Study } \\ \text { Setting: } & \text { Tertiary Private University Hospital }\end{array}$

Participants: Records of 188 patients who presented with epistaxis at the emergency room as well as in-patient admissions and referrals due to epistaxis from January 2017 to December 2017 were reviewed.

Results: There were a total of 188 patients who presented with epistaxis with a male to female ratio of 2:1. Peak incidence was noted in young children aged 0-10 years old and again rising in adults above 60 years of age. The most common cause of epistaxis was noted to be trauma $(56,29.79 \%)$ followed by hypertension $(41,21.81 \%)$ and mucositis at $(38,20.21 \%)$. Conservative management were done in majority of the cases $(187,99.47 \%)$ with an overall success rate of $95.19 \%$ (178 out of 188$)$.

Correspondence: Dr. Francisco Jesus V. Lerma, Jr.

Department of Otorhinolaryngology

Head and Neck Surgery

University of Santo Tomas Hospital

España Blvd., Manila 1015

Philippines

Phone: (632) 7313001 loc. 2411

Email:ust_enthns@yahoo.com

The authors declare that this represents original material, that the manuscript has been read and approved by all the authors, that the requirements for authorship have been met by each author, and that each author believes that the manuscript represents honest work.

Disclosures: The authors signed disclosures that there are no financial or other (including personal) relationships, intellectual passion, political or religious beliefs, and institutional affiliations that might lead to a conflict of interest.

Presented at the Philippine Society of Otolaryngology Head and Neck Surgery Descriptive Research Contest. October 22, 2018, Maynila Ballroom, The Manila Hotel, Manila.

Conclusion: One of the most common emergencies that people may encounter in their lifetime is epistaxis. Understanding the demographic profile, etiology, intervention and treatment outcome of patients with epistaxis is essential for the establishment of cost-effective treatment guidelines, protocols and preventive strategies. Health education remains to be a key in reducing morbidity and mortality resulting from epistaxis.

\section{Keywords: epistaxis; etiology, demographics, treatment, treatment outcome}

Epistaxis is reported to be one of the most common otorhinolaryngological emergencies worldwide and is frequently encountered in general practice as well. It is estimated to occur in $60 \%$ of persons during their lifetime with approximately $6 \%$ requiring medical attention. ${ }^{1,2}$ Epistaxis may present in various ways; as an acute emergency, a chronic problem of recurrent bleeding or as a symptom of a systemic disorder. It is commonly divided into anterior or posterior depending on the site of origin. Anterior epistaxis accounts for more than $80 \%$ of cases and arises from damage to the Kiesselbach's plexus along the anterior nasal septum. ${ }^{2}$ Epistaxis in this area 
is usually self-limiting and easier to control. Posterior epistaxis which includes damage to the Woodruff's plexus are less common occurring in $10 \%$ of patients and may be more challenging to control. ${ }^{3}$ No matter the type or severity of the epistaxis the correct management is always essential.

Although epistaxis has been dealt with for centuries, its management remains a challenge for both the public and many health professionals. A survey done among clinical staff at the emergency department of a national teaching hospital showed that only $38.1 \%$ of the respondents demonstrated the correct site for manual compression of the nose. ${ }^{4}$ Indeed, management of epistaxis causes great anxiety not only to patients and their relatives but to health care workers and physicians as well. Several studies on the causes, treatment, and outcome of patients with epistaxis have been done worldwide however, there is a paucity of local data available. A literature search of MEDLINE, HERDIN and Google Scholar using the keywords "epistaxis" and "Philippines" yielded studies among the pediatric population only. There were no local studies available that examine the clinical profile of patients with epistaxis across all age groups.

This study aims to determine the demographic profile, etiology and treatment outcome of patients presenting with epistaxis across all ages in our local setting. Specifically, it seeks to identify the most common age range and gender distribution, the most common underlying cause of epistaxis in our setting and the success and failure rate of surgical and non-surgical interventions for epistaxis.

\section{METHODS}

With Institutional Review Board approval, a retrospective review of records of all patients who presented with epistaxis during a period of one year from January to December 2017 was carried out. This included cases of epistaxis seen at the emergency room of the clinical and private division, as well as both admissions and in-patient referrals from all services severe enough to warrant urgent consult. Excluded were those patients presenting with epistaxis at the out-patient department since majority of patients seen at the OPD were inactive cases. Patient anonymity was protected in the collection of data. Confidential patient data was known only to the authors and each patient was assigned a reference number for identification known only to the investigator.

Demographics such as age and gender, as well as the etiology/cause of bleeding were collected and tabulated. The treatment rendered was also noted for each of the cases. Treatment outcome was assessed based on the criteria by Basheer, et al. ${ }^{5}$ which included the following: Successful treatment was defined as no readmission or consult at the emergency room within 24 hours of discharge or no recurrence of epistaxis for 24 hours following nasal packing removal. Failure of treatment was defined as readmission or consult at the emergency room within 24 hours of hospital discharge or persistent epistaxis after nasal packing for 24-48 hours.

Data collected were analyzed with descriptive statistics using Microsoft Excel for Mac 2016 Version 16.12. (Microsoft Corp., Redmond, CA, USA). The age, gender, etiology, treatment rendered and treatment outcome were collected and tabulated. The actual number of cases for each was divided by the total population and multiplied by 100 to obtain percentages.

\section{RESULTS}

A total of 188 records of patients who presented with epistaxis from January 2017 - December 2017 were included in this study. There were a total of 125 males (66.5\%) and 63 females (33.5\%) with a male to female ratio of 2:1. Ages ranged from 9 months to 82 years old with a peak incidence in young children aged 0-10 years old and again in adults above 60 years of age. One hundred forty six (146) patients $(77.7 \%)$ presented at the emergency room department while 42 patients (22.3\%) were in-patient admissions and referrals.

Overall, the most common cause of epistaxis was noted to be trauma $(56,29.79 \%)$. Trauma included cases of epistaxis due to direct or blunt injury from sports, vehicular accidents, mauling and fall. This was followed by hypertension (41, 21.81\%) and mucositis (38, 20.21\%). Other causes included digital manipulation $(32,17.02 \%)$, other systemic illnesses $(7,3.72 \%)$, intranasal mass or tumor $(5,2.66 \%)$, blood dyscrasia including anticoagulant use $(4,2.13 \%)$, secondary to dengue fever $(4$, $2.13 \%)$ and iatrogenic injury $(1,0.53 \%)$.

For children 10 years and below, the most common cause was digital manipulation $(13,36.11 \%)$ followed by trauma $(11,30.55 \%)$. Trauma remained to be the most common etiology for epistaxis among patients aged 11-50 years old. For both the middle and old age population (51-60 and 61above), hypertension was the most common etiology. (Table 1)

Table 1. Causes of Epistaxis according to Age Group

\begin{tabular}{|c|c|c|c|c|c|c|c|c|c|}
\hline $\begin{array}{c}\text { Age } \\
\text { range }\end{array}$ & Trauma & $\begin{array}{l}\text { Hyper- } \\
\text { tension }\end{array}$ & $\begin{array}{c}\text { Muco- } \\
\text { sitis }\end{array}$ & $\begin{array}{c}\text { Digital } \\
\text { Mani- } \\
\text { pulation }\end{array}$ & $\begin{array}{c}\text { Other } \\
\text { systemic } \\
\text { causes }\end{array}$ & \begin{tabular}{|l|} 
Mass/ \\
Tumor
\end{tabular} & $\begin{array}{c}\text { Blood } \\
\text { dyscrasia }\end{array}$ & $\begin{array}{l}\text { Dengue } \\
\text { Fever }\end{array}$ & $\begin{array}{l}\text { e latro- } \\
\text { genic }\end{array}$ \\
\hline 0-10 & 11 & 0 & 9 & 13 & 2 & 0 & 0 & 1 & 0 \\
\hline $11-20$ & 10 & 0 & 3 & 8 & 1 & 1 & 0 & 1 & 0 \\
\hline $21-30$ & 12 & 3 & 10 & 1 & 1 & 0 & 0 & 1 & 0 \\
\hline $31-40$ & 9 & 1 & 7 & 3 & 0 & 0 & 0 & 0 & 1 \\
\hline $41-50$ & 7 & 6 & 3 & 2 & 2 & 1 & 0 & 1 & 0 \\
\hline $51-60$ & 4 & 8 & 3 & 3 & 0 & 3 & 1 & 0 & 0 \\
\hline 61 & 3 & 23 & 3 & 2 & 1 & 0 & 3 & 0 & 0 \\
\hline
\end{tabular}


Non-surgical measures were the main intervention in majority of the cases $(187,99.47 \%)$. Conservative measures such as manual digital compression, application of ice packs and topical vasoconstrictors as well as control of hypertension provided relief in the majority (177, $94.15 \%$ ) of patients. Anterior nasal packing were warranted in 3.19\% (6 out of 188 ) of patients while $2.13 \%$ (4 out of 188) of patients required posterior nasal packing. Only 1 out of 188 patients $(0.53 \%)$ required surgical intervention with cauterization of bleeders.

The overall success rate for non-surgical treatment was $95.19 \%$ (178 out of 188 patients). Out of 177 patients treated conservatively with manual digital compression, application of ice packs, topical vasoconstrictors and control of hypertension, 169 (95.48\%) had no recurrence of epistaxis within 24 hours while only 8 patients (4.52\%) were considered failure of treatment. All patients who underwent anterior nasal packing were treated successfully while $75 \%$ of patients (3 out of 4 patients) who had posterior nasal packing were also successfully treated. Surgical management on the other hand also had a $100 \%$ success rate. (Table 2 )

Table 2. Treatment Outcomes of Non-Surgical and Surgical Intervention

\begin{tabular}{|c|c|c|c|c|}
\hline $\begin{array}{c}\text { TREATMENT } \\
\text { MODALITY }\end{array}$ & $\begin{array}{c}\text { NO. OF } \\
\text { PATIENTS }\end{array}$ & $\begin{array}{c}\text { NO. OF } \\
\text { PATIENTS } \\
\text { SUCCESFULLY } \\
\text { TREATED }\end{array}$ & $\begin{array}{c}\text { SUCCESS } \\
\text { RATE } \\
(\%)\end{array}$ & $\begin{array}{c}\text { FAILURE } \\
\text { RATE } \\
(\%)\end{array}$ \\
\hline NON-SURGICAL & 187 & 178 & 95.19 & 4.81 \\
\hline $\begin{array}{c}\text { Manual Compression, } \\
\text { Ice Pack +Topical } \\
\text { Vasoconstrictor }\end{array}$ & 177 & 169 & 95.48 & 4.52 \\
\hline Anterior Nasal Packing & 6 & 6 & 100 & 0 \\
\hline Posterior Nasal Packing & 4 & 3 & 75 & 15 \\
\hline SURGICAL & 1 & 1 & 100 & 0 \\
\hline $\begin{array}{c}\text { Endoscopic } \\
\text { Cauterization }\end{array}$ & 1 & 1 & 100 & 0 \\
\hline Arterial Ligation & 0 & 0 & 0 & 0 \\
\hline
\end{tabular}

\section{DISCUSSION}

Epistaxis, defined as an acute hemorrhage from the nostril, nasal cavity or nasopharynx is considered the most common otorhinolaryngologic emergency affecting up to $60 \%$ of the population in their lifetime with up to $6 \%$ warranting medical attention. ${ }^{1,2}$ In this retrospective review of records, epistaxis was noted to be more common in men with a male to female ratio of 1.98:1. Globally, there is a male preponderance in epistaxis as shown in different studies as well. ${ }^{6,7}$

In our study, peak incidence of epistaxis was noted among the pediatric age group less than 10 years of age and it was again observed among those above 60 years of age. The increased incidence in the pediatric age population in our setting may be due to the fact that they are more prone to digital manipulation or nose picking, and are also often victims of trauma such as minor falls. A rise in the old age group was also seen and may be attributed to factors such as hypertension and poor blood pressure control.

Most of the underlying causes of epistaxis are preventable. Our study showed that trauma was the most common cause closely followed by hypertension and mucositis. The high incidence of traumatic epistaxis across all age groups warrants emphasis on the importance of rhinologic assessment among all trauma patients.

Hypertension was noted to be the second most common cause of epistaxis overall in our setting, present in $21.81 \%$ of cases, and also the most common cause among the middle age (51-60 years) and older age group (61 years above). Epistaxis in the elderly have a diverse etiology with hypertension as the most common etiological factor as seen in other studies as well. ${ }^{8}$ This may explain its increased incidence among patients more than 60 years of age, and emphasizes the importance of proper compliance with antihypertensive medications as well as the need for regular check-ups and blood pressure monitoring.

Initial assessment of a patient presenting with epistaxis should focus on the general status of the patient vital signs and cardiopulmonary stability. Once these are established, a more thorough history and physical examination may proceed. ${ }^{3}$ The treatment of epistaxis is based on the site and degree of bleeding. Treatment modalities are divided into two groups: conservative or non-surgical and surgical approaches. ${ }^{1}$ Non-surgical approaches have been reported to stop the bleeding in the majority of the cases which was likewise evident in our study with a $95.19 \%$ success rate. Surgical treatment is reserved for ongoing hemorrhage that fails conservative interventions.

In our study, the diagnosis of epistaxis was based on a thorough clinical history and complete physical examination with special emphasis on the nose and oral cavity to identify the origin and site of bleeding. All patients were initially treated conservatively and surgical intervention was considered only when conservative management failed to control the epistaxis. Conservative management was utilized in a stepwise fashion. Patient positioning with the head bent forward was ensured to avoid swallowing of blood and subsequent nausea and vomiting. Manual digital compression over the nasal ala was initially done and is recommended as well in studies as the first step in controlling simple anterior nose bleeding in all stable patients. Application of ice compress over the forehead and nape area, together with the use of a locally applied vasoconstrictor in the form of Oxymetazoline $0.025 \%$ nasal drops (3-5 drops per nostril) for children 
and $0.05 \%$ nasal spray (2 sprays per nostril) for adults (provided that blood pressure was controlled) to aid in the cessation of bleeding was then done. This method provided relief of epistaxis in $95.48 \%$ (169 out of 177 patients) of cases with no recurrence noted in 24 hours. In resource-poor areas where facilities and specialists are limited, this finding suggests that majority of epistaxis presenting at the emergency department may be controlled with proper first aid measures. This may serve as a guide in educating health care workers and patients as well when faced in a situation with epistaxis.

Anterior nasal packing was used in 3.19\% (6 out of 187 patients) of our cases with a good outcome. Contrary to other studies which state that anterior nasal packing was the most frequent modality of treatment, ${ }^{7}$ nasal packing may be uncomfortable and may be responsible for a plethora of complications. Other studies show that the failure rate of nasal packing has been reported to be up to $52 \%$, and the rate of re-bleeding increased to $70 \%$ in patients with known bleeding disorders. ${ }^{9}$ The insertion of the nasal packing itself may be traumatic and can further induce bleeding in areas different from the primary site. Hence, anterior nasal packing is reserved for cases when manual compression failed to control the bleeding. Given the limited number of patients that underwent nasal packing in this study, a significant correlation between the type of nasal packing used and treatment outcome could not be derived.

Posterior nasal packing was done in only $2.13 \%$ (4 out of 188) cases. Out of the 4 patients who underwent this intervention, only 1 needed surgical management through endoscopic cauterization of bleeders. Indeed, monopolar cauterization under endoscopic guidance for control of posterior epistaxis may offer a safe and effective management for refractory nasal bleeding. Electrocautery has a reported efficacy of $90 \%{ }^{2}$ When done inside the operating room under general anesthesia, patient safety and comfort is ensured and this can be easily performed by a trained physician. Arterial ligation is necessary only in intractable cases of epistaxis when all measures fail. In our study, no surgical ligation of vessels was required. There was also no mortality recorded in this series.

One of the most common emergencies that people may encounter in their lifetime is epistaxis. Fortunately, most of the underlying causes of epistaxis are preventable. In our setting, trauma remains the most common etiology, closely followed by hypertension and mucositis. Non-surgical treatment remains the first line management in controlling epistaxis in our setting. Conservative measures such as proper head positioning, manual digital compression, application of ice compress and use of topical vasoconstrictors alone are sufficient in controlling a majority of cases with a success rate of $95.48 \%$. It is safe, cost-effective and efficient in arresting the bleeding. Understanding the causes, treatment and outcome of these patients is essential for the establishment of preventive strategies and treatment guidelines and protocols. In resource poor communities where facilities and specialists are limited, training of health care workers and proper health education on the first aid measures on epistaxis may be helpful and life-saving.

\section{REFERENCES}

1. Diamond L. Managing epistaxis. JAAPA. 2014 Nov; 27(11):35-39. DOI: 10.1097/01. JAA. $0^{\text {TM }} 000455643.58683 .26 ;$ PMID: 25303882.

2. Melinte V, Musteata O, Sarafoleanu C. Epistaxis management - our point of view and literature review. Romanian Journal of Rhinology. 2017 Oct-Dec; 7 (28): 207-2013. DOl: 10.1515/rjr-20170022.

3. Andreeff, R. Epistaxis. JAAPA. 2016 Jan; 29(1):46-47. DOI: 10.1097/01.JAA.0000473373.47749.5f; PMID: 26704654.

4. Mugwe P, Kamau KJ, Nyambaka OK. Knowledge, attitude and practice in first aid management of epistaxis by accident and emergency clinical staff at Kenyatta national hospital. East Cent Afrc JSurg. 2014 Mar-Apr; 19(1): 17-21.

5. Basheer NK, Jaya C, Sabir VT. Epistaxis: etiological profile and treatment outcome in a teaching hospital in South India. Int J Otorhinolaryngol Head Neck Surg. 2017 Oct; 3(4): 878-84. DOI: http:// dx.doi.org/10.18203/issn.2454-5929.ijohns20174099.

6. Varshney S, Saxena RK. Epistaxis: A retrospective clinical study. Indian J Otolaryngol Head Neck Surg. 2005 Apr; 57(2): 125-129. DOI: 10.1007/BF02907666; PMCID: PMC3450961; PMID: 23120148.

7. Gilyoma J, Chalya PL. Etiological profile and treatment outcome of epistaxis at a tertiary care hospital in Northwestern Tanzania: a prospective review of 104 cases. BMC Ear Nose Throa Disord. 2011 Sep 5; 11:8. DOI: 10.1186/1472-6815-11-8; PMID: 21892930 PMCID: PMC3175172.

8. Sharma K, Kumar S, Islam T, Krishnatreya M. A retrospective study on etiology and management of epistaxis in elderly patients. Arch Med Health Sci. 2015; 3(2): 234-8. DOI: 10.4103/23214848.171911.

9. Traboulsi H, Alam E, Hadi U. Changing Trends in the Management of Epistaxis. Int J Otolaryngol. 2015; 2015: 263987. DOI: 10.1155/2015/263987; PMID: 26351457 PMCID: PMC4553192.

10. Pallin DJ, Chng YM, McKay MP, Emond JA, Pelletier AJ, Camargo CA Jr. Epidemiology of epistaxis in US emergency departments, 1992 to 2001. Ann Emerg Med. 2005 Jul; 46(1): 77-81. DOl: 10.1016/j.annemergmed.2004.12.014; PMID: 15988431.

11. Beck R, Sorge M, Schneider A, Dietz A. Current approaches to epistaxis treatment in primary and secondary care. Dtsch Arztebl Int. 2018 Jan 8; 115(1-02): 12-22. DOI: 10.3238/arztebl.2018.0012 PMID: 29345234 PMCID: PMC5778404.

12. Morgan DJ, Kellerman R. Epistaxis: evaluation and treatment. Prim Care. 2014 Mar; 41(1):63-73. DOI: 10.1016/j.pop.2013.10.007; PMID: 24439881. 